\title{
Reversible Paraneoplastic Encephalomyelitis Associated with a Benign Ovarian Teratoma
}

\author{
R. Blaine Taylor, Warren Mason, Kester Kong, Richard Wennberg
}

\begin{abstract}
Background: Paraneoplastic encephalomyelitis (PEM) is a well characterized, and typically irreversible, paraneoplastic syndrome, usually associated with small cell lung cancer or other malignancy. We describe a case of a young woman with a benign ovarian teratoma who presented with a reversible PEM. Case report: A 24-year-old woman presented with a three week history of memory impairment, unusual behavior, personality changes, auditory hallucinations, hypersomnolence and binocular diplopia. On admission she was disoriented and inattentive with impaired short term memory. Small doses of lorazepam (1 mg), given for episodic agitation, repeatedly induced multidirectional bilateral nystagmus and a skew deviation, but her neurological examination was otherwise normal. A left-sided pelvic mass was palpable. Brain MRI pre- and post-gadolinium was normal. There was a mild CSF pleocytosis and an EEG showed minimal bilateral background activity irregularities. There were no other laboratory abnormalities. Two weeks after admission, she clinically deteriorated developing central respiratory failure and a flaccid paraplegia. Repeat MRI showed an area of increased T2 weighted signal in the medulla and three similar areas in the spinal cord. Following removal of her tumor, treatment with high dose corticosteroids and intravenous immunoglobulin, she ultimately made a full recovery. Pathology revealed the tumor to be a benign ovarian cystic teratoma. Conclusions: This is the first report of a reversible PEM seen in association with a benign tumor, in this case a mature ovarian teratoma. Presumably, an immune response directed against neural elements of the teratoma crossreacted with normal brain, brainstem and spinal cord antigens to cause neurologic symptoms. Tumor removal was followed by neurologic recovery.
\end{abstract}

RÉSUMÉ: Encéphalomyélite paranéoplasique réversible associée à un tératome bénin de l'ovaire. Introduction: L'encéphalomyélite paranéoplasique (EMP) est un syndrome paranéoplasique réversible bien caractérisé, habituellement associé à un cancer du poumon à petites cellules ou à un autre type de cancer. Nous décrivons le cas d'une jeune femme porteuse d'un tératome bénin de l'ovaire et qui a présenté une EMPréversible. Présentation clinique: Une jeune femme de 24 ans a consulté pour un problème de mémoire évoluant depuis 3 semaines, un comportement inhabituel, des changements de la personnalité, des hallucinations auditives, de la somnolence et de la diplopie binoculaire. À l'admission, elle était désorientée et inattentive et présentait un déficit de la mémoire à court terme. De petites doses de lorazépam $(1 \mathrm{mg})$, administré pour contrôler une agitation épisodique, ont induit à plusieurs reprises un nystagmus bilatéral multidirectionnel et une disjonction des mouvements du regard. Son examen neurologique demeurait par ailleurs normal. La palpation de l'abdomen a révélé une masse pelvienne gauche. L'IRM cérébrale pré et post-gadolinium était normale. Il existait une pléiocytose légère du LCR et l'ÉEG montrait des irrégularités minimes bilatérales de l'activité de fond. Il n'y avait pas d'autre anomalie de laboratoire. Deux semaines après l'admission, elle a présenté une défaillance respiratoire centrale et une paraplégie flasque. Des études IRM répétées ont montré une région de signal pondéré en T2 augmenté dans le bulbe rachidien et trois zones semblables dans la moelle épinière. Suite à l'ablation de sa tumeur, elle a reçu des doses élevées de corticostéroïdes et des immunoglobulines intraveineuses. Elle a finalement récupéré complètement. L'examen anatomopathologique de la tumeur a montré qu'il s'agissait d'un tératome kystique bénin de l'ovaire. Conclusions: C'est le premier rapport d'un cas d'EPM réversible observé en association avec une tumeur bénigne, soit un tératome ovarien mature. Il semble qu'une réponse immunitaire dirigée contre des éléments nerveux du tératome a induit une réaction croisée avec des antigènes du tissu cérébral normal, du tronc cérébral et de la moelle épinière provoquant des symptômes neurologiques. Elle a récupéré complètement suite à l'ablation de la tumeur.

Can. J. Neurol. Sci. 1999; 26: 317-320

Paraneoplastic syndromes are remote effects of cancer that are not directly related to metastases, metabolic or nutritional derangements, or side effects of therapy. There is now increasing evidence that autoantibodies produced against the malignancy cross-react with normal brain antigens, ${ }^{1}$ though the pathogenesis of the paraneoplastic syndromes may actually be related to cellmediated autoimmunity. ${ }^{2}$ A clinical approach to the paraneoplastic syndromes has been outlined by Dalmau, ${ }^{3}$ which requires that one of four criteria be met for diagnosis: (1) the presence of a typical paraneoplastic syndrome in a patient known to have an appropriate underlying cancer, (2) the presence of a

\footnotetext{
From the Division of Neurology, The Toronto Hospital, University of Toronto, ON RECEIVEDMARCH 29, 1999. ACCEPTED INFINALFORMJUL Y 2, 1999 Reprint requests to: Dr. R. Wennberg, The Toronto Hospital, EC8-022, 399 Bathurst Street, Toronto, Ontario, Canada M5T2S8
} 
neurological disorder associated with a typical antineuronal antibody in serum or CSF, (3) the presence of a neurological disorder which resolves when the cancer is discovered and adequately treated, or (4) pathological findings typical of a paraneoplastic disorder.

Paraneoplastic encephalomyelitis (PEM) is a well characterized paraneoplastic syndrome, most commonly associated with small cell lung cancer. Its manifestations are variable, and PEM can present as a limbic encephalitis, ${ }^{4}$ which has also been reported in cases of Hodgkin's disease, thymoma, uterine, breast, prostate, bladder, testicular, and colon cancers, ${ }^{5-11}$ as well as in several cases where no malignancy was found..$^{4,12-16}$

There have been two recent case reports of immature ovarian teratomas presenting in association with limbic encephalitis. ${ }^{17,18}$ In both cases, there was a mild CSF pleocytosis with no infectious etiology identified and no antineuronal antibodies detected. There was stabilization or some degree of recovery of each patient's symptoms after tumor removal.

In addition, there has been one case report of a malignant mediastinal teratoma where autopsy revealed findings consistent with PEM. No other causative agents were detected, nor were autoantibodies to brain tissue found. ${ }^{19}$

We describe here a case of a reversible PEM which occurred in a young woman with a benign ovarian teratoma.

\section{Case Report:}

A 24-year-old right-handed woman of Chinese descent presented with a three week history of memory impairment, unusual behaviour, and personality changes. One week prior to admission, she developed hypersomnolence, delusional thinking and auditory hallucinations. She complained of forgetfulness and of binocular diplopia in all gazes of direction. Because of this, she tended to keep her left eye closed. She was never febrile but had suffered some symptoms of cough and was treated with an antibiotic one week prior to admission.

She was previously well but had had an asymptomatic pelvic mass detected on routine exam one month prior to admission which on an ultrasound performed at another centre was felt to be a dermoid cyst. She was awaiting gynecological consultation.

She had no history of smoking, alcohol or other drug use, no history of toxic exposures and no HIVrisk factors. She was on no medications, had no known drug allergies, and had no recent immunizations.

A brain CT done one week prior to admission was normal but an EEG was reported to show intermittent bilateral temporal slow wave activity.

On admission, her blood pressure was 120/80, heart rate 84 and regular, and temperature $37.6^{\circ} \mathrm{C}$. Her general medical examination was unremarkable apart from a large palpable left-sided pelvic mass. She appeared lethargic but was easily roused. There was no meningismus. She was disoriented to time and place. 5-minute recall was impaired although long-term memory was intact. She had decreased concentration and attention with difficulty following 2 or 3 step commands. Language function was normal. Pupils and fundi were normal. After a small dose of lorazepam (1mg sublingual) for agitation, she had prominent gazeevoked nystagmus in all directions and an obvious skew deviation, which persisted for several hours before dissipating. This induced oculomotor phenomenon was reproducible to repeated small doses of benzodiazepines given infrequently for agitation over the subsequent four days. Oculomotor movements in the absence of benzodiazepines appeared normal despite her ongoing symptom of binocular diplopia.
The remainder of her neurological examination was entirely normal.

Her initial investigations included normal $\mathrm{Hb}$, WBC, platelets, electrolytes, creatinine, BUN, glucose, calcium, magnesium, phosphate, INR, PTT, ESR, AST, ALT, ALP and bilirubin. Hepatitis B and C serology were negative. Thyroid indices were normal. Serum ANAwas positive at 1:40 speckled pattern with normal C3 and C4 complement levels. Chest x-ray was normal. Urinalysis was normal.

On day 2, an EEG was mildly abnormal with rare bilaterally synchronous slow wave discharges anteriorly. A repeat EEG on day 4 was within normal limits. A brain MRI scan pre- and post-gadolinium administration was normal. CSF examination showed 8 million WBC/L (87\% lymphocytes, $13 \%$ monocytes), 1 million $\mathrm{RBC} / \mathrm{L}$, glucose 4.3 $\mathrm{mmol} /$ Land protein $0.31 \mathrm{~g} / \mathrm{L}$. Cryptococcal antigen, India Ink, bacterial, fungal and viral cultures were all negative. PCR for CMV, HSV and $\mathrm{EBV}$, and IFA for CMV were negative. CSF cytology was negative for malignant cells. Serum and CSF VDRL were non-reactive. Serum was negative for HIV1 and 2. Pelvic ultrasound and CTscan of the abdomen and pelvis revealed a $14 \times 10 \times 10 \mathrm{~cm}$ complex cystic pelvic mass arising from the left adnexa with a $4 \mathrm{~cm}$ mural nodule of variable attenuation with foci of calcification felt to be most likely an ovarian dermoid. No ascites or omental cake was seen. Her beta HCG was negative, AFP tumor marker $<5 \mu \mathrm{g} / \mathrm{L}$ and Ca125 was normal. FSH, LH, HGH, prolactin, ACTH and cortisol levels were also normal.

On day 15, she developed dysphagia and subsequently had a respiratory arrest requiring intubation and mechanical ventilation. CXR revealed no pulmonary disease. She was not breathing spontaneously but would trigger the ventilator to command suggesting central hypoventilation. She was awake, alert and would follow commands. She had vertical and horizontal gaze-evoked nystagmus. Her cough and gag reflexes were decreased. There were no other cranial nerve abnormalities and no motor or sensory deficits. Her nystagmus decreased over the next few days but she developed restricted vertical gaze, more so in upgaze than downgaze. She began breathing spontaneously the following day.

The tentative working diagnosis had been, from early after her admission, a paraneoplastic rhombencephalitis/limbic encephalitis, given the normal MRI scan and normal laboratory results, apart from the minimal CSF pleocytosis and EEG changes. The initial gynecological opinion obtained in hospital recommended postponement of surgical excision of the patient's pelvic mass until her neurologic/psychiatric symptomatology had resolved. After the neurologic deterioration and respiratory arrest, repeat gynecological consultation was obtained and the patient underwent a right salpingooophorectomy and omental biopsy on day 17 .

The surgical pathology revealed a unilocular cystic ovary with a multiloculated mammillary pole measuring $5.5 \mathrm{~cm}$ in diameter, which contained black hairs. Serial sectioning of the mammillary pole revealed multiple cystic spaces ranging from 1 to $7 \mathrm{~mm}$ in diameter. There were a variety of tissue types identified and the mesenchymal tissue was cellular but there were no areas of immaturity seen. There were no abnormalities of the fallopian tube or omentum and the ovarian tumor was diagnosed as a mature cystic teratoma. Peritoneal fluid cytology was negative for malignant cells.

Her neurological status remained stable until day 20 when she became more drowsy and developed a flaccid paraplegia with a T5 sensory level. Repeat brain and spinal cord MRI showed one area of increased $\mathrm{T} 2$-weighted signal in the dorsal aspect of the medulla measuring $8 \mathrm{~mm}$, and three areas of similar signal intensity in the spinal cord: one at $\mathrm{C} 4-5$, the second at $\mathrm{T} 3$ and the third at $\mathrm{T} 8-9$. The remaining neural structures were entirely normal.

She was started on methyl-prednisolone $1 \mathrm{~g}$ IV daily for five days followed by a gradual taper of oral prednisone starting at $60 \mathrm{mg}$ daily. Her clinical status continued to deteriorate. By day 28 , she was comatose with no motor response to pain and no eye opening. She had intact brainstem reflexes except for absent cough and gag reflexes and she required tracheostomy for continued ventilatory support. 
Serial CSF studies showed a range of 8 to 23 WBCs per cubic millimeter with a lymphocytic predominance between 87 and $98 \%$; 0 to $25 \mathrm{RBCs}$; glucose 3.1 to $4.2 \mathrm{mmol} / \mathrm{L}(2.2-4.4)$ and protein 0.31 to 0.61 $\mathrm{g} / \mathrm{L}(0.15-0.45)$. CSF albumin was $100 \mathrm{mg} / \mathrm{L}(134-237 \mathrm{mg} / \mathrm{L})$ and $\mathrm{IgG}$ was 19 (4-51).

A repeat EEG on day 30 showed a mild generalized disturbance of background activity. EMG and NCS done on day 31 showed no evidence of peripheral nerve involvement.

Because of the lack of response to high dose intravenous steroids and the patient's poor clinical status, intravenous immune globulin (IVIG) was given at a dose of $400 \mathrm{mg} / \mathrm{kg} /$ day for five days (days 30-35). By day 36 she had improved significantly, was awake and alert, and following commands. Extraocular eye movements were full and there was no nystagmus. She continued to have a poor cough and gag but cranial nerves were otherwise normal. Over the following two and a half weeks, she continued to progressively improve and was discharged from the ICU on day 55. She was never administered acyclovir.

A repeat brain and spinal cord MRI on day 42 pre- and postgadolinium was unchanged from the study done on day 21.

Serum and CSF samples, along with the pathology specimen, were sent for further analysis for antineuronal antibodies (Dr. Jerome Posner; Memorial Sloan-Kettering Cancer Center, New York, NY). Using Western blot analysis, no antineuronal antibodies were detected when tested against normal human brain.

During the remainder of her hospital stay, the patient received extensive physiotherapy and was discharged on day 79 , ambulating with a walker, to a rehabilitation facility. At that time, she remained entirely amnestic of the events which had occurred between the time she was admitted until shortly before she was transferred out of the ICU.

At six month follow-up, she had fully recovered apart from a mild burning truncal dysesthesia which was gradually improving. An MRI with gadolinium showed a decrease in the size of her previous lesions with no enhancement.

\section{DISCUSSION}

The clinical presentation of our patient was very similar to the cases described by Aydiner et al. ${ }^{17}$ and Nokura et al. ${ }^{18}$ with, initially, a pure limbic encephalopathy with features of impaired memory and judgement, behavioural changes, emotional outbursts and delusional thinking. In all three cases, CSF revealed a mild lymphocytosis, there was no evidence of underlying infection, and no antineuronal antibodies were detected.

The main difference in the present case is that the tumor was benign, i.e., no immature components were identified at pathology. It is not impossible that a microscopic malignant component of this tumor could have been missed on pathological examination, and there have been cases of paraneoplastic syndromes where the carcinoma was only detectable microscopically. ${ }^{11,20,21}$ However, careful review of our tumor did not show any immature features and we feel this is unlikely the case. It is also conceivable that the tumour was a coincidental finding and that the neurological syndrome was due to another disease process. However, we were unable to demonstrate any infectious etiology and serological studies for a systemic vasculitis were negative. The initial normal brain MRI, three and a half weeks after onset of symptoms, excludes from diagnostic consideration a para- or postinfectious acute disseminated encephalomyelitis. ${ }^{22}$ In combination, her clinical presentation, CSF profile, EEG, neuroimaging studies, and improvement following treatment by tumor resection argues strongly in favour of a paraneoplastic etiology.

Our patient initially continued to deteriorate despite resection of her tumor and she did not appreciably respond to high dose steroids. However, she began to show dramatic and sustained clinical improvement six days following institution of IVIG, a total of 19 days following removal of the teratoma. The relative contribution of our interventions is impossible to determine but the timing of her improvement suggests that IVIG may have hastened her recovery. Whether or not resection of her tumor contributed to the sustained benefit remains speculative, albeit plausible. Spontaneous improvement has been reported in rare cases of paraneoplastic limbic encephalitis, with or without positive anti-Hu antibodies: ${ }^{22,23}$ this confounding factor will limit definitive evaluation of treatment responses in any paraneoplastic syndrome.

In summary, this is the first reported case of a patient with a benign ovarian teratoma with clinical features of an encephalomyelitis including limbic encephalitis, brainstem involvement and a multifocal myelitis. Presumably, an immune response directed against non-malignant neural elements of the teratoma cross-reacted with normal brain, brainstem and spinal cord antigens to cause the neurologic symptoms. Resolution of the neurologic symptomatology ultimately followed removal of the underlying tumor in conjunction with steroid therapy and IVIG administration.

\section{REFERENCES}

1. Voltz RD, Posner JB, Dalmau J, Graus F. Paraneoplastic encephalomyelitis: an update of the effects of the anti-Hu immune response on the nervous system and tumour. J Neurol Neurosurg Psychiatry 1997; 63: 133-136.

2. Benyahia B, Liblau R, Merle-Béral H, et al. Cell-mediated autoimmunity in paraneoplastic neurological syndromes with anti-Hu antibodies. Ann Neurol 1999; 45: 162-167.

3. Dalmau J. Paraneoplastic syndromes of the nervous system: diagnostic approaches. In: Vinken PJ, Bruyn GW, eds. Handbook of Clinical Neurology, Vol. 69. Amsterdam: Elsevier Science, 1997: 319-328.

4. Dalmau J, Graus F, Rosenblum MK, Posner JB. Anti-Hu-associated paraneoplastic encephalomyelitis/sensory neuronopathy. Medicine 1992; 71: 59-72.

5. Deodhare S, O'Connor P, Ghazarian D, Bilbao JM. Paraneoplastic limbic encephalitis in Hodgkin's disease. Can J Neurol Sci 1996; 23: 138-140.

6. Antoine JC, Honnorat J, Anterion CT, et al. Limbic encephalitis and immunological perturbations in two patients with thymoma. J Neurol Neurosurg Psychiatry 1995; 58: 706-710.

7. Henson RA, Hoffman HL, Urich H. Encephalomyelitis with carcinoma. Brain 1965; 88: 449-464.

8. Baloh RW, DeRossett SE, Cloughesy TF, et al. Novel brainstem syndrome associated with prostate carcinoma. Neurology 1993; 43: 2591-2596.

9. Scully RE, Mark EJ, McNeely BU. Case records of the Massachusetts General Hospital. N Engl J Med 1985; 313: 249-257.

10. Burton GV, Bullard DE, Walther PJ, Burger PC. Paraneoplastic limbic encephalopathy with testicular carcinoma. A reversible neurologic syndrome. Cancer 1988; 62: 2248-2251.

11. Tsukamoto T, Mochizuki R, Mochizuki H, et al. Paraneoplastic 
cerebellar degeneration and limbic encephalitis in a patient with adenocarcinoma of the colon. J Neurol Neurosurg Psychiatry 1993; 56: 713-716.

12. Langston JW, Dorfman LJ, Forno LS. "Encephalomyeloneuritis" in the absence of cancer. Neurology 1975; 25: 633-637.

13. Kohler J, Hufschmidt A, Hermle L, Volk B, Lucking CH. Limbic encephalitis: two cases. J Neuroimmunol 1988; 20: 177-178.

14. Daniel SE, Love S, Scaravilli F, Harding AE. Encephalomyeloneuropathy in the absence of a detectable neoplasm. Clinical and postmortem findings in three cases. Acta Neuropathol 1985; 66: 311-317.

15. Horoupian DS, Kim Y. Encephalomyeloneuropathy with ganglionitis of the myenteric plexuses in the absence of cancer. Ann Neurol 1981; 11: 628-632.

16. Torvik A, Sletteb M. Encephalomyelitis with polyneuropathy. Acta Neurol Scand 1980; 61: 287-297.

17. Aydiner A, Gurvit H, Baral I. Paraneoplastic limbic encephalitis with immature ovarian teratoma. J Neurooncol 1998; 37: 63-66.

18. Nokura K, Yamamoto H, Okawara Y, et al. Reversible limbic encephalitis caused by ovarian teratoma. Acta Neurol Scand 1997; 95: 367-373.

19. Kawaguchi K, Kishida S, Okeda R, Funata N, Koike M. Encephalomyeloneuritis with mediastinal germ cell tumor. Acta Pathol Jpn 1988; 38: 351-359.

20. Kaplan AM, Itabashi HH. Encephalitis associated with carcinoma. Central hypoventilation syndrome and cytoplasmic inclusion bodies. J Neurol Neurosurg Psychiatry 1974; 37: 1166-1176.

21. Corsellis JAN, Goldberg GJ, Norton AR. Limbic encephalitis and its association with carcinoma. Brain 1968; 91: 481-496.

22. Caldemeyer KS, Smith RR, Harris TM, Edwards MK. MRI in acute disseminated encephalomyelitis. Neuroradiology 1994; 36: 216220.

23. Byrne T, Mason WP, Posner JB, Dalmau J. Spontaneous neurological improvement in anti-Hu associated encephalomyelitis. J Neurol Neurosurg Psychiatry 1997; 62: 276-278.

24. Alamowitch S, Graus F, Uchuya M, et al. Limbic encephalitis and small cell lung cancer. Clinical and immunological features. Brain 1997; 120: 923-928. 